
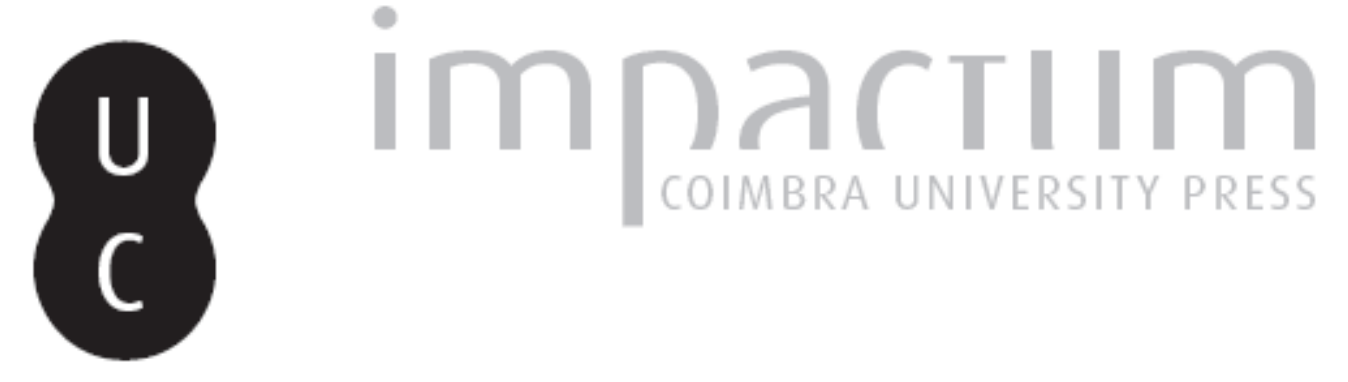

\title{
Memórias: razões e sentido de uma aprendizagem em arquitectura
}

Autor(es): $\quad$ Tavares, Domingos

Publicado por: Editorial do Departamento de Arquitetura

URL persistente:

URI:http://hdl.handle.net/10316.2/37316

DOI:

DOI:http://dx.doi.org/10.14195/1647-8681_3_4

Accessed : $\quad$ 26-Apr-2023 04:43:12

A navegação consulta e descarregamento dos títulos inseridos nas Bibliotecas Digitais UC Digitalis, UC Pombalina e UC Impactum, pressupõem a aceitação plena e sem reservas dos Termos e Condições de Uso destas Bibliotecas Digitais, disponíveis em https://digitalis.uc.pt/pt-pt/termos.

Conforme exposto nos referidos Termos e Condições de Uso, o descarregamento de títulos de acesso restrito requer uma licença válida de autorização devendo o utilizador aceder ao(s) documento(s) a partir de um endereço de IP da instituição detentora da supramencionada licença.

Ao utilizador é apenas permitido o descarregamento para uso pessoal, pelo que o emprego do(s) título(s) descarregado(s) para outro fim, designadamente comercial, carece de autorização do respetivo autor ou editor da obra.

Na medida em que todas as obras da UC Digitalis se encontram protegidas pelo Código do Direito de Autor e Direitos Conexos e demais legislação aplicável, toda a cópia, parcial ou total, deste documento, nos casos em que é legalmente admitida, deverá conter ou fazer-se acompanhar por este aviso.

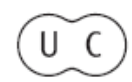




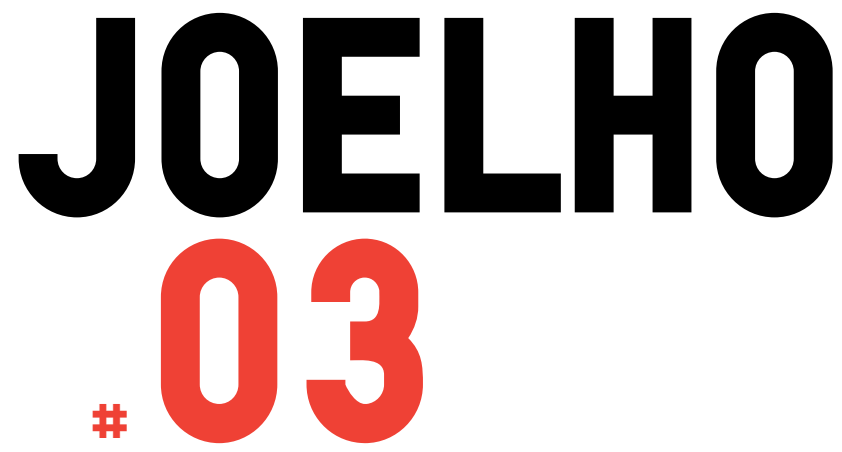

\section{VIAGEM-MEMÓRIAS: APRENDIZAGENS DE ARQUITECTURA}

Coordenação:

Alexandre Alves Costa

Domingos Tavares

Exposição Viagem

Exposição Memórias

Luis Mansilla

Alexandre Alves Costa

Domingos Tavares

SCA FoL DiNG
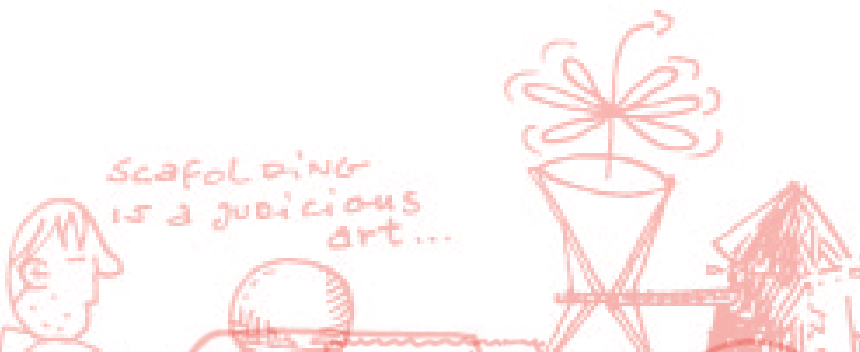

Jorge Figueira

José Miguel Rodrigues

José António Bandeirinha José Fernando Gonçalves

Paulo Providência

Gonçalo Canto Moniz Armando Rabaça

Patrícia Miguel

Bruno Gil

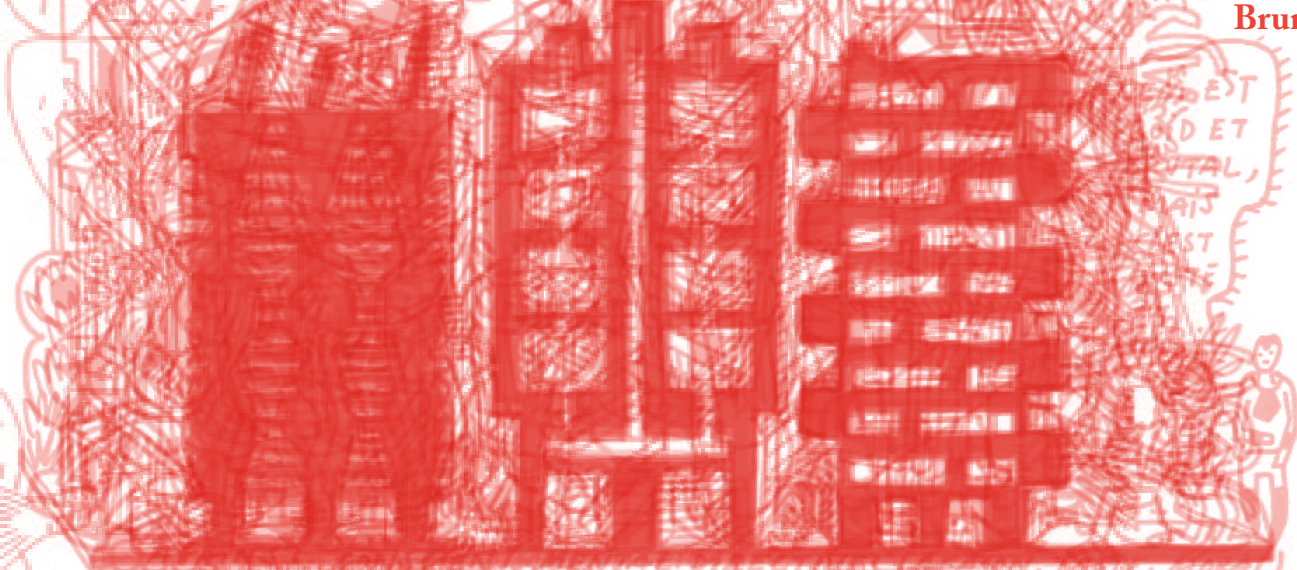

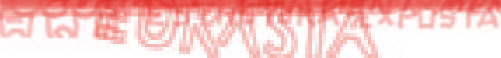




\section{Domingos Tavares \\ Memórias - razões e sentido \\ de uma aprendizagem \\ em arquitectura}


Conheci Carlos de Almeida no final de 1961. Cheguei a Coimbra com presunção de estudante e ambição de me orientar, logo que possível, para a arquitectura. Sopunha-me ser capaz de desenhar e fui oferecer os meus préstimos em trabalho à hora ao mais activo arquitecto da cidade. Admirei a firmeza com que conduzia a execução das suas obras. Senti a força da modernidade do prédio da Rua da Sofia onde estava instalado o seu escritório-atelier. Percebi a convicção com que se entregava ao seu ofício numa linha de afirmação militante da corrente moderna, perseguindo as poéticas de Le Corbusier ou Niemeyer em nome do progresso. E o firme compromisso que a si próprio se impôs de acreditar sempre no seu país e no seu povo, aceitando as utopias do futuro. Só mais tarde me apercebi de quanto depois veio a sofrer na defesa dos seus ideais. Com simpatia e compreensão inventou para mim algum trabalho, talvez desnecessário, dando-me o alento que não sei se a qualidade do desenho realizado teria merecido.

Nesse Outono de 1961 saiu no renovado periódico estudantil "Via Latina" uma Carta Aberta à Jovem Portuguesa que incendiou a Academia. Era apenas um ingénuo apelo à consciência cívica das novas gerações, mas nem por isso deixou de provocar um debate emocionante entre forças políticas situacionistas e os paladinos de uma cultura aberta a novos tempos e valores. $\bigcirc$ ambiente extremou-se e ocorreram greves com as consequentes cargas policiais. Vários colegas foram despachados para a guerra de África, se não optaram rapidamente pelo exílio intelectual de Paris. Em Fevereiro, os Jograis de S. Paulo deram um recital de poesia no anfiteatro das Letras e revelaram, para gáudio de uma multidão de estudantes que esgotou completamente a sala, que o desaparecido paquete Santa Maria, raptado em pleno Atlântico, se dirigia para Cabo Verde. Algum tempo depois, naquele mesmo palco, o saudoso Professor José Carlos Ferreira de Almeida ensinava a uma plateia igualmente repleta o processo de descoberta da verdadeira representação do espaço através da história da pintura do Renascimento italiano. A massa estudantil estava sempre disponível, tanto para enfrentar alegremente os mais chatos discursos dos inflamados dirigentes da Academia nas Assembleias Magnas, como os cavalos da polícia de choque. Tão interessada em aprender o que não se ensinava nas aulas, como presente nos concertos do Orfeão ou do ciclo de música da Gulbenkian. Activa no teatro, espectadora no cinema, gastando horas de conversa nas esplanadas da Praça de República.

Inscrevi-me no curso de desenho do Círculo de Artes Plásticas. Afinal não tinha assim tanta confiança nas minhas capacidades pessoais quando pensava virar-me para o mundo da arquitectura, apesar das palavras de conforto de Carlos de Almeida. Ao cimo da Avenida Sá da Bandeira estava em vias de conclusão a nova sede da Associação Académica. Aquela construção trazia-me à lembrança novas arquitecturas como as que visionava nos livros de uma estante da livraria do Porto que visitava quando apanhava boleia para a cidade grande. Deles fixei nomes de artistas criadores como Frank Lloyd

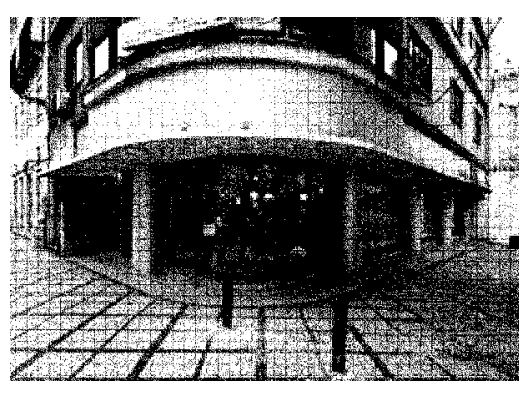

1. Carlos de Almeida - Edifício na Rua da Sofia, Coimbra,1954 (fotografia João Armando Ribeiro) 


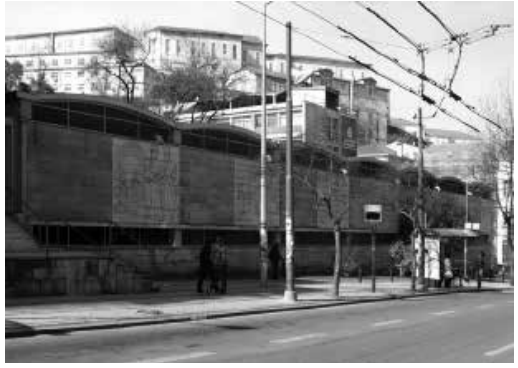

2. Alberto Pessoa e João Abel Manta - Instalações Académicas da U.Coimbra, 1954/62

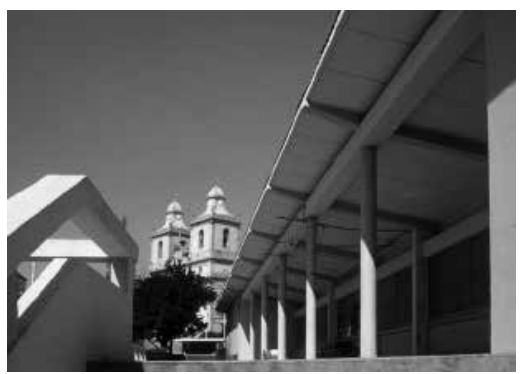

3. Januário Godinho - Mercado Municipal de Ovar
Wright e Le Corbusier e casas, principalmente casas a preto e branco, fluxos de água entre florestas ou estranhas caixas de vidro encasteladas em jogos de luz e sombra. Num sossegado domingo infiltrei-me pelos interiores da obra para dar saída a uma natural curiosidade e pude ver um largo terreiro ganhando forma por dentro da diversidade da envolvente construída. Entre paredes e caminhos imaginei um lugar de maior conforto do que o sombrio pátio das letras, inacessível, impedindo os namorados no corredor de ver para além dos vidros foscos da grande casa cúbica. Nem imaginava que um dos arquitectos autor das Instalações Académicas, Alberto Pessoa, também fosse responsável pela equipa que projectou as enormes massas de pedra que eram a Biblioteca Geral e a Faculdade de Letras, envolvendo o pátio das mamudas. Os lugares de futuro que agora surgiam anunciavam-se mais dinâmicos, mais alegres, onde todos nos poderíamos sentir por dentro de espaços vividos com a frescura do ar livre.

Em Ovar, alguns anos antes, acompanhei as obras do novo mercado, quando todas as madrugadas corria para o comboio a caminho do Liceu. Era o progresso da minha terra que estava em jogo quando se soltavam as cores vermelhas e amarelas pelas paredes e vidros dos pavilhões ondulantes a formar novas praças. Talvez venha daí, desses tempos de criança quase rapaz, um sentimento de alegria por ver nascer as formas de um outro estar, prolongamento das ruas onde sempre rebentavamos as botas em jogos e correrias. Alguma coisa me fez pensar que o arquitecto das novas instalações académicas seria amigo, companheiro de ideias, colega de escola ou de grupo do arquitecto do Mercado de Ovar. Afinal não era assim. Ecléticos ambos, concebendo arquitecturas em função das novidades do momento e dos destinos programados para cada obra, eles colocavam a maestria da sua acção na capacidade de mobilizar as formas de organização do espaço com recurso ao desenho que expressa no papel a força das ideias para criação das formas, independentemente dos sistemas de construção dominante, pedra ou betão, madeira ou vidro. Livres de aceitar fazer a obra entre o sinal de convivialidade ou de afirmação da autoridade e poder. É por aí que começamos a compreender porque encontramos o mesmo arquitecto, Januário Godinho, nos projectos do Mercado de Ovar e do Palácio da Justiça seu vizinho. Ou porque Alberto Pessoa figura como autor na execução da estratégia definida por Cristino da Silva para a Biblioteca Geral e Faculdade de Letras de Coimbra e porque é o primeiro nome da sociedade de arquitectos do projecto das instalações académicas.

Uma arquitectura dita do Movimento Moderno, entendida como corrente internacional, vinha-se impondo em Portugal depois da II Grande Guerra, interessando especialmente os arquitectos mais jovens que, de diferentes perspectivas, se sentiam comprometidos com as ideias de mudança e progresso. Cabe aqui lembrar o espírito de abertura que se vivia na Escola de Belas Artes do Porto depois da década de quarenta, apoiada no impulso modernista de Carlos 
Ramos, com a consequente dinamização do espírito artístico virado para as novas correntes. Se de início foi a acção dos artistas do grupo dos Independentes sob o impulso do pintor Júlio Pomar que colocou arquitectos abstraccionistas nos domínios da pintura, como Fernando Lanhas ou Nadir Afonso, depressa os estudantes de arquitectura se deixaram apanhar pela moda do moderno, imitando mais Niemeyer ou Reidy do que Corbusier, sensíveis à poética do movimento e à sensualidade das formas que a divulgação do complexo turístico de Pampulha ou do Conjunto Residencial Pedregulho no Rio de Janeiro ajudou a colocar na mesa de trabalho dos estudantes do Porto. Uma versão popular da corrente internacional da arquitectura moderna, descontraída e muito colorida, varreu então algumas cidades do norte e litoral português graças ao traço das novas gerações de arquitectos saídos da Escola do Porto.

Carlos de Almeida foi um entusiasta do grupo dos Independentes do Porto. Companheiro de Escola e amigo pessoal de Nadir Afonso, o caminho que escolheu não foi o da descoberta de um mundo artístico para lá das fronteiras de um Portugal fechado mas, desde o princípio, o do projecto de arquitectura actuando em Coimbra, área da sua comunidade natal. Aqui chegado como jovem profissional depressa se envolveu em polémicas acerca da orientação urbanística seguida pelas autoridades locais, invocando os princípios de um planeamento integrado ao serviço do progresso e do bem estar dos cidadãos.

Enquanto alguns dos antigos companheiros enveredavam pela arte abstracta, assumiu como referência principal posições mais próximas do neorealismo de Júlio Pomar no que elas constituiam uma afirmação de compromisso com as classes populares. Não abdicou da profunda amizade com Nadir, que foi o suporte profissional do atelier da Rua da Sofia nos anos amargos de prisioneiro político. Mas, para Carlos de Almeida, a utopia deixou de estar ligada à descoberta da perfeição das formas, para se inserir no mundo das ideias revolucionárias que procuram complexos caminhos para transformar o mundo, na esperança que o futuro seja o de uma sociedade com menos desiguldade e injustiças. Aprendi, também com ele, que o possível proveito individual se apaga perante a grandeza dos mais nobres projectos colectivos.

O meu conhecimento da vida era ainda muito restrito. Desde pequeno entendia mal as estranhas razões que levaram companheiros de escola e de rua a desaparecer do nosso convívio de rapazes porque iam trabalhar com os pais para as fainas da pesca ou do campo. Porque viviam em casas de madeira pequenas e perigosamente inclinadas, pousadas directamente sobre a areia, tanto as da praia como as da vila. No verão fascinavam-me as operações de mar, os barcos coloridos, as mulheres de negro descalças ajudando à faina. Como poderia a arquitectura moderna intervir num ciclo social de mudança, quando as questões sociais pareciam ser bem mais complexas do que decorria do discurso formal da arte, mesmo se entendido nas diversas intervenções da antropologia cultural, como me pareceu evidente através da

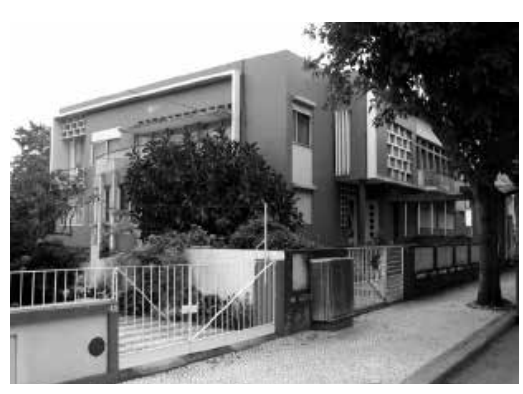

4. Sérgio Gonçalves - Casa em Aveiro, 1954/56 


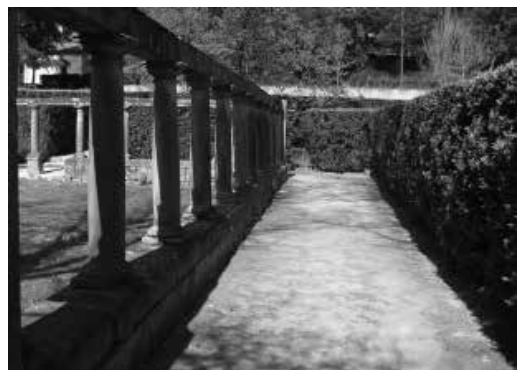

5. Fernando Távora - Ruínas do Claustro nos jardins da Quinta da Conceição, 1956/60 publicação em fascículos de um Inquérito à Arquitectura Popular em Portugal que um amigo de Ovar coleccionava. Ali apareceram os palheiros da Tocha e de Quiaios, iguais às casas dos pescadores da minha terra, e não me parecia grande coisa enaltecer as construções precárias em que vivia tanta gente.

A sabedoria dos povos e a inteligência colectiva são o fermento em que germina a obra de arte. Com Fernando Távora aprendi a entender a cultura como algo mais profundo que o simples deleite estético, mais complexo que um somatório de exposições e conferências de consagrados intelectuais. E que as razões da arte estão intimamente ligadas às razões da vida. Por exemplo, que a poesia como arte de interpretação da realidade, mesmo se recorre à construção melódica, à acentuação rítmica, à alusão simbólica para extrair da complexidade dos costumes as linhas básicas para a compreensão emotiva do mundo, é o primeiro domínio do pensamento arquitectónico. Com ele aprendi a importância da síntese dos valores contraditórios, colocando no mesmo plano o popular e o erudito, o antigo e o moderno, o particular e o universal. Enfim, reconhecendo a tradição como estrutura de conhecimento necessário à formação do pensamento criativo e, portanto, como factor de progresso.

Cheguei finalmente ao curso de arquitectura, na Escola do Porto, em Outubro de de 1962. Na exposição dos trabalhos escolares que assinalou a abertura das aulas, estavam incluídos projectos de professores. Nessa época, a figura tutelar para os colegas mais velhos era Carlos Ramos. Mas os que chegaram nesse ano, depressa identificaram a capacidade comunicativa e a clareza das demonstrações de Távora, bem como o discurso de responsabilidade antropológica enunciado por Arnaldo Araújo, quer quando ensinavam sobre as mesas de desenho ou quando explanavam conhecimento sob forma discursiva em aulas teóricas. Era outro o mundo das ideias que se respirava no jardim das Belas Artes, a S. Lázaro. Sobre as mesas dos estudantes começavam a rarear as formas copiadas dos magasines da moda internacionalista e os alunos dos dois primeiros anos do curso desenhavam ferozmente nos ambientes populares, para se contaminarem com as condições de vida das populações das Fontaínhas, da Sé ou de Miragaia. Desenhavam os bairros por fora e por dentro. Varandas e azulejos para traduzir o emaranhado típico da construção transformada em popular, louças e camas assinalando o interior de miséria das casas arruinadas.

Naquele tempo, enquanto estudantes solidários e empenhados na própria formação, andavamos em grupos à procura dos sinais da mudança, olhando as novidades anunciadas ou rabiscando em esquissos as obras que pressentiamos como intervenções qualificadas. No eixo de Matosinhos a Leça da Palmeira, pelas periferias do Porto, ía-mos ficando extasiados com as inúmeras descobertas que anunciavam outros entendimentos da arquitectura que, curiosamente, pareciam ficar discretamente encobertos na mancha extensa da grande cidade. 
Neste processo de vasculhar na produção visível da arquitectura recente, coube-me a sorte de ser integrado como colaborador estudante no escritório profissional de Fernando Távora. Durante dois anos, a partir do Outono de 1963, couberam-me tarefas típicas de aprendiz sob a tutela do mestre e seus oficiais arquitectos. Copiar desenhos a tinta, fazer cópias, ajudar nos levantamentos à fita, arrumar os arquivos. Mais do que legendar os imensos rolos dos originais de projectos produzidos até então, entusiamou-me a missão de identificar e ordenar centenas de fotografias e muitos desenhos produzidos pela equipa da zona 1 do Inquérito à Arquitectura Popular em Portugal. Pude entender que na pesquiza antropológica para a organização do espaço, o urbano e o rural podem assumir a mesma importância como lição do passado para a resolução do presente e, fenómeno perturbante, como as concepções eruditas se podem emiscuir nas práticas populares e contaminar os supostos modos ancestrais, ditos vernaculares. A matriz compositiva de construções tão elementares como uma pequena fachada de rua em Braga ou as varandas graníticas do Soajo, são dignas da evolução clássico/barroca dos Paços da nobreza minhota enriquecida pela introdução de nova economia agrícola.

A contaminação parece assumir o papel principal no progresso das artes. Se em determinadas épocas, por razões filosóficas, estéticas ou de natureza político-social, os actores da inteligência interventiva se ocupam de revalorizar as tradições ancestrais expressas nas formas e objectos criados no âmbito dos ofícios populares, importa reconhecer o que neles resulta de saberes colectivos estabilizados e o que é contaminação de factores exógenos. Mesmo as comunidades rurais, tradicionalmente mais estáveis, são frequentemente sugeitas a violentas pressões transformadoras, reconstruindo-se em função dos quadros de mudança. Foi o caso da revolução do milho que atingiu em força o noroeste português no século XVII, alterando toda a panóplia de organizações do edificado, incluindo materiais, métodos e instrumentos da acção quotidiana. E, seguramente, mechendo com os costumes e tabús sociais. A arte, mais ou menos popular, é disso testemunha. Essa mesma arte popular foi, também ela, profundamente marcada por sinais externos, absorvendo modernidades que a tornavam mais valiosa ao olhos dos clientes vindos da cidade e do turismo intelectual.

O pavilhão de ténis da Quinta da Conceição é um exemplo claro dessa relação mútua que Távora sempre soube estabelecer entre os valores das culturas preexistentes e os sinais de transformação oriundos do debate nos grandes foruns internacionais da arquitectura. Pequena construção sem uma razão de utilidade evidente, sobrou espaço para um ensaio teórico, quase um manifesto de defesa da nova corrente arquitectónica que toma a cultura material dos povos como lição e estímulo ao desenvolvimento da arte moderna. Os pilares de granito, as paredes rebocadas a branco, as estruturas de madeira suportando o telhado cerâmico de beirada saliente, constituem os ingredientes extraídos de tradições construtivas concretas para organizar uma outra 


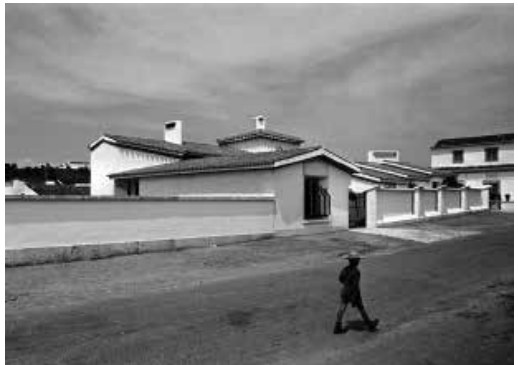

6. Nuno Portas - Nuno Teotónio Pereira e Pedro Vieira De Almeida - Moradia em Vila Viçosa, 1960 (fotografia Atelier Teotónio Pereira) linguagem arquitectónica de cariz absolutamente neoplástica, na linha das experiências renovadoras que surgiam então em alguns países da periferia cultural europeia, como Alvar Aalto na Finlândia, James Stirling em Inglaterra ou Gian Carlo di Carlo em Itália.

Assim, não foi por acaso que passado alguns anos, pertendendo eu próprio assumir orgulhosamente a condição de discípulo, desenhei a primeira casa que me foi encomendada, na mira do exemplo do mestre, num exercício de interpretação das formas mais apelativas do corpo central das Escolas Primárias do Bairro do Cedro em Vila Nova de Gaia. A partir da decomposição dos volumes resultantes do cruzamento dos telhados, formam-se planos para a inserção de janelas em posição assimétrica, como quem recorda a plasticidade sugerida pela corrente neo-vernacular que fez escola pela Europa moderna sob o impulso de arquitectos como Fernando Távora. As mesmas paredes brancas, o uso das madeiras tradicionais, as mesmas coberturas cerâmicas encaixandose em planos inclinados, a economia de vãos nas superfícies mais expostas ao público para melhor afirmação ostensiva dos volumes puros, em oposição às transparências alpendradas nas transições privadas para os pátios interiores.

Razões estritamente pessoais me transferiram para a Escola de Belas Artes de Lisboa no final de 1965. Estava em construção a nova sede da Fundação Calouste Gulbenkian, mas já podíamos passear pelos jardins em fase de consolidação. Começava a sair uma versão mais inglesa, em betão e metal escuro, do que fora um projecto comandado pelo mesmo Alberto Pessoa das Instalações Académicas de Coimbra. Nesse ano os Beatles tocavam em todas as rádios e os jovens licenciados de boas famílias com expectativas e influência, preferiam a Inglaterra para correr aos doutoramentos. Arquitectos ilustres, internacionais, tutelavam uma linguagem mais fina para a sede da Fundação, com os trajes frios do norte. Em matéria de música, Amália cantava David Mourão Ferreira com fados compostos por Alain Oulman. "Por teu livre pansamento, foram-te longe encerrar".

Na Escola de Lisboa também se reorganizava o ensino da arquitectura. O mais jovem Professor, Nuno Portas, tomava a responsabilidade da didáctica do Projecto, fomentando nos alunos a prática do juízo crítico, a curiosidade pelas teorias sociais e pelos métodos científicos. Mandou-nos ler Intentions in Architecture de Christian Norberg-Schulz e Community and Privacy de Serge Chermayeff e Christopher Alexander. De Chermayeff extraímos aquela fantástica casa com pátios que oferecia independência real aos filhos das famílias americanas, sem perda da ideia de solidariedade. Propôs-se desenvolver uma experiência pedagógica em colaboração com os Professores da Escola do Porto. O Alexandre Alves Costa no LNEC e eu num dos grupos de estudantes da FAUTL, poderiamos funcionar como barómetro de eficácia dos métodos ensaiados. Depois dos tratadistas do maneirismo de quinhentos, depois do exercício da ordenação matemática no final do barroco e da crença nos compêndios 
neoclássicos franceses, era outra vez a vontade da ciência, agora oriunda de Inglaterra pela divulgação do método de Manchester para ensinar arquitectura, que Nuno Portas queria ensaiar.

Entre a ciência e a espera necessária em tempo de recolha dos dados objectivos para resolver um problema, aprendemos com Nuno Portas a organizar a informação, a explorar caminhos alternativos, a formular hipóteses contraditórias e a submete-las ao crivo do juízo crítico verificando a adequação de cada ideia à satisfação dos pressupostos elencados para cada fase, tanto em matéria de funções programadas como quanto às condições económicas e materiais de realização ou quanto à satisfação das regras genéricas de montagem do cenário urbano. No entanto, era desde logo compreensível um claro predomínio da matéria funcional, por ser a mais compreensível e a que os estudos sistemáticos melhor poderiam explorar. De resto a teoria funcionalista constituía nesses anos a doutrina dominante, que os especialistas da antropologia cultural acabavam por reforçar na interpretação dos diferentes instrumentos ao serviço dos modos de produção, enquanto suporte da sobrevivência de cada comunidade autónoma. Assim como os sociólogos da revolução urbana, que se limitavam a acolher e introduzir nas suas metodologias de investigação os factores objectivos detectáveis nos movimentos sociais, sem questionar a força imanente da subjectividade do ser humano.

De resto, a própria intervenção profissional da equipa a que estava ligado Nuno Portas no projecto para um conjunto de habitação em bairro na urbanização de Olivais Sul, em Lisboa, era uma resposta incómoda aos pressupostos da designada habitação social, espécie de construção para pobres localizada nas novas periferias. Arquitecto culto sempre interessado na teoria e na razão profunda das coisas, transportava consigo a sensação de incumprimento na defesa de métodos científicos, não tanto por falta de convicção no valor da ciência, mas por falta de resultados perceptíveis quanto à capacidade de revolucionar as condições de vida a partir da arquitectura. Sempre inquieto, passava da função à forma e da forma arquitectónica à problemática urbana, percorrendo os caminhos da sociologia ou da política como saída alternativa para defender ideais de futuro. No emaranhado dos blocos soltos de Olivais Sul, surgiu um pedacinho de rua oferecendo perspectivas controladas para a percepção variada da imagem repetida das casas. Não era bem assim que estavamos a interiorizar o discurso racionalizado, teórico, sistematizador, que o professor parecia querer defender.

Ao contrário das convicções de pendor mais científico trabalhadas por Nuno Portas, onde entra a pesquisa tipológica como matéria de reflexão sistemática na tentativa de fixação de um manual de boas práticas, o trabalho de Vitor Figueiredo que se desenrolava a par do de Nuno Teotónio Pereira e constituia também matéria de reflexão conjunta, apoiava-se principalmente na sensibilidade instintiva para descobrir as melhores soluções no sentido de bem servir os utentes de cada grupo

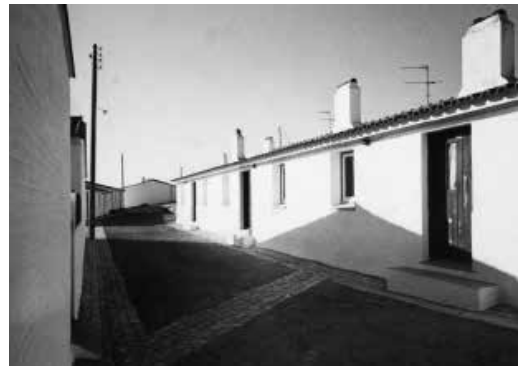

7. Vitor Figueiredo e Vasco Lobo - Bairro de Habitações Económicas, Benvente, 1962 (SIPA) 
social a que previsivelmente se destinava a obra em concreto, à luz da cultura própria e modos de vida reconhecíveis no momento. É este um caminho mais próximo do processo criativo da arquitectura de autor, irrepetível, mesmo se enterdermos a transformação do espaço construído como um contínuo de acções em coerência civilizacional, controlada a todos os níveis pelos sistemas dominantes de produção. Esta nossa Escola de Coimbra teve a felicidade de contar durante alguns poucos anos com a colaboração de Vitor Figueiredo, o arquitecto que nunca projectava sozinho, professor sem carreira que punha a simplicidade e o rigor ideológico como lição aos seus alunos.

No verão de 1967 regressei definitivamente ao Porto. Era nossa convicção que só existiam perspectivas profissionais nas cidades grandes e a competição na capital era demasiado feroz, ainda mais difícil para quem não dominava completamente as subtis regras do jogo das relações de poder. Afinal, no Porto, ainda funcionava o Teatro Experimental apesar da morte de António Pedro. O Cine-Clube continuava interventivo e dinâmico, apenas tinham desaparecido os concertos pagos pela Gulbenkian, que concentrava agora na sede lisboeta todo o potencial do seu petróleo. Mas em S. Lázaro ainda se houvia falar de Alvar Aalto e mesmo de Reidy. Em Setembro acompanhei as filmagens exteriores do segundo filme de Paulo Rocha, Mudar de Vida, centrado sobre o tema da incapacidade de sobrevivência da economia da pesca artesanal e a inadaptação dos pescadores à situação do operariado da indústria, sujeita a regras de funcionamento e dependência como as que os arquitectos e outros profissionais das artes criativas têm dificuldade de suportar.

Foi só depois da Revolução de Abril que tive oportunidade de aplicar, em projecto real e rapidamente realizado, muitas das ideias de sistematização compositiva suportada por desenho analítico à luz de um programa para casas de baixo custo. Curiosamente, tal aconteceu quando a iniciativa pública municipal se apoiava num financiamento especial oferecido pelo governo, num programa inventado por Nuno Portas. Pareceu-me uma solução perfeita para um esquema de renda económica, adaptada aos costumes de vivência familiar da gente humilde da minha terra. Dispunha de um pátio privado, de entradas independentes com circulação autónoma de serviço, muita transparência entre os cómodos interiores da habitação virados ao sol e o exterior aberto ao céu. $\bigcirc$ grande sucesso foi o preço a que se chegou, graças à repetição e ligeireza dos componentes construtivos. O desastre maior foi a mudança de política, quando a Câmara Municipal, proprietária do conjunto, resolveu ela própria capitalizar vendendo as casas. Claro que os moradores pobres não as podiam comprar e as habitações até eram muito apelativas. Com direitos assumidos pelos novos proprietários actuando individualmente e dispondo de dinheiro supérfluo, foram substituidos revestimentos, abertos vãos irracionais, incorporadas garagens, num descontrolo total da imagem. Oxalá os seus actuais utentes se sintam felizes. 
Entrei para a equipa docente da Escola de Belas Artes do Porto como segundo assistente, dois meses depois de me terem conferido o diploma de arquitecto. Fiquei a trabalhar directamente com Viana de Lima, cabendo-me acompanhar de perto os alunos do quinto ano. Admirei o modo sensível como Viana organizava as sessões de crítica conjunta, não tanto pelo sistema de reunir o grupo à volta do projecto de um dos estudantes, discutindo-o, e daí seguindo para a proposta seguinte. Este era, como continua a ser, o método mais comum no sistema de ensino prático de arquitectura, a que Nuno Portas já chamou um dia o "ensino boca a boca". Nem mesmo por se assemelhar à prática dos velhos mestres das Beaux-Arts, quando pegavam no lápis grosso ou no carvão e riscavam as correcções sobre os originais dos pobres aprendizes, sem dizer uma palavra. É que Viana riscava mesmo por cima dos mais estimados desenhos mas falava, comentando as correcções. As suas observações, na maior parte das vezes muito duras, nem sempre tinham uma lógica compreensível. Eram produto de uma reacção comandada pelo instinto compositivo, onde entrava a escala dos espaços, o ritmo das formas, a fluidez natural dos usos, a compreensão dos critérios construtivos. Numa sequência de subjectividades opinativas, em tudo contrária a qualquer razoabilidade técnico-científica.

Por essa época, como convinha a quem queria ser arquitecto, a maioria dos estudantes desenhava furiosamente. Nenhuma palavra, em qualquer conversa, deixava de ser sublinhada por um risco. Nos cadernos de apontamentos, nos bilhetes do autocarro ou nos guardanapos de papel, sucediam-se os esquissos à procura de soluções para os problemas que eram postos. Em passeio ou viagens organizadas desenhávamos arquitecturas, mais ou menos clássicas, mais ou menos modernas. Não era necessária a autoridade disciplinadora dos professores exigindo uma certa quantidade de trabalho, porque os candidatos à profissão traziam o bichinho de pôr sistematicamente ideias no papel. Encarreirados, desde pequenos, porque tinham geito, depressa entendiam como construir um caminho próprio sob o estímulo do exemplo e do debate que a escola proporcionava. Nestas Escolas de Belas Artes as ciências puras ficavam longe, mesmo se a sociedade tivesse dificuldade em entender os reais limites da arquitectura como profissão técnica, porque sempre mais próxima das ciências humanas. Nunca ouvi Viana de Lima pedir um desenho aos seus alunos, mas eles apareciam sempre, numerosos, em cima da mesa.

Outro importante caminho da aprendizagem era o conhecimento directo da obra dos mestres. A primeira notícia de que um determinado professor ia tomar conta de um grupo de trabalho, levava imediatamente os estudantes a espiolhar todos os seus projectos, os sucessos reconhecidos e eventuais peças menores. Na década de setenta Viana de Lima tinha um passado de prestígio com quarenta anos de actividade profissional e não faltavam exemplos de belas construções no terreno. Ainda assim, fazia questão de levar os alunos

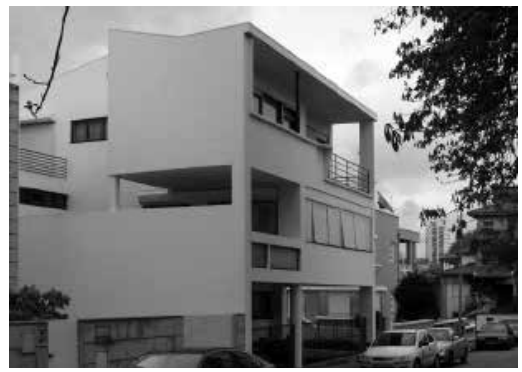

8. Viana de Lima - Moradia no Porto, $1949 / 51$ 
a conhecer as obras que trazia em curso, acabando as visitas em belos almoços patrocinados pelos respectivos empreiteiros. Era vê-lo num terreno quase vazio onde só despontavam os ferros das armaduras do arranque dos pilares saindo das valas de fundação, a mostrar a importância dos passos perdidos numa futura Casa da Justiça, a relação volumétrica entre a sala de audiências e os serviços de apoio, a incidência do sol nos gabinetes e secretarias. Diziam que Viana de Lima copiava Le Corbusier, mas o que estava à vista de todos era uma obra original, de cuidada organização e bela expressão plástica. Funcionalista, talvez. Racional, apenas quanto baste na criação dos lugares de vida das pessoas.

Uma das mais curiosas atitudes de Viana de Lima era o manifesto interesse por todas as novidades que corriam regularmente pelo mundo da arquitectura, através de revistas de grande circulação, congressos internacionais ou mesmo livros como manifestos distribuídos à atenta inteligência da especialidade. Já o conhecemos sugestionado pelo movimento brutalista promovido dentro dos CIAM, os Congressos Internacionais da Arquitectura Moderna. Depois foram as Megaestruturas propostas por Kenzo Tange para a baía de Tóquio ou Yona Friedman para cobrir o centro de Paris. Numa aula podemos ouvir falar do seu interesse pelo movimento Archigram e de como novas perspectivas no entendimento da construção poderiam levar a soluções arquitectónicas inovadoras capazes de resolver os problemas da superpopulação nas cidades do futuro. Versão não muito clara do creditar na competência em arquitectura com independência em relação aos sistemas construtivos dominantes em cada momento e distinta das diferentes correntes estéticas, mais clássicas ou modernas. De algum modo, por ali se justificava uma abertura consciente ao ecletismo.

Assim se compreende o projecto para as Escolas Primárias de Bragança, Prémio Nacional de Arquitectura em 1961, numa data em que tudo indicava entender a sequência da obra de Viana de Lima nos caminhos dominantes das correntes internacionalistas. Bragança foi para Viana de Lima, à entrada da década de sessenta, uma referência marcante, pela dimensão de algumas encomendas e pelo facto de acompanhar alguns jovens, incluindo colaboradores do seu atelier como foi o caso de Sérgio Fernandez, no entusiasmo militante pela arquitectura popular como lição de fundo para um novo pensar arquitectónico. $O$ Inquérito à Arquitectura Popular tinha produzido os seus frutos e na Escola do Porto sucediam-se os trabalhos de tese como aprofundamento dessa temática. É que a equipa do Inquérito à Zona 2 tinha valorizado em especial a pesquiza sobre os mais pequenos e remotos aglomerados rurais, tomando-os como exemplo de um complexo problema de ordem cultural sobre o qual se fundamenta a acção da arquitectura. Viana de Lima era muito sensível a esse tema.

Exemplo notavelmente desenvolvido da posição culturalista apoiada nos estudos antropológicos e na realidade do mundo rural, foi a tese de Arnaldo Araújo, sobre o habitat rural em Bragança, 
defendida na ESBAP em 1957. Dava continuidade ao projecto para uma comunidade agrícola apresentada ao X Congresso dos CIAM em 1956, numa equipa que integrava Viana de Lima e Fernando Távora.

O belíssimo desenho dos cata-ventos, do pintor António Quadros, ilustra o sentido muito aberto que orientava as preocupações dos arquitectos da geração formada no Porto depois da grande guerra. Tomava dos mais velhos, como Arménio Losa, Cassiano Barbosa ou Viana de Lima, o rigor ideológico associado ao sentido da responsabilidade social. Das mais recentes preocupações assumidas colectivamente nos meios intelectuais promotores de outro entendimento da arquitectura, ressaltava a preocupação científica, que já referimos também em Nuno Portas, e o avanço para uma interdependência da acção colectiva na formação do saber, onde o campo artístico implicava a integração de pintores e escultores nas equipas de estudo sobre arquitectura.

Num quadro de valores tão aberto e ao mesmo tempo tão complexo, a utilização de instrumentos de controlo executivo para atingir a perfeição sonhada da beleza universal, como se ainda fosse possível acreditar nessa possibilidade teorizada pela filosofia clássica, colocou na ordem do dia a tese do Modulor. Todos sabíamos da admiração que Viana de Lima nutria pela figura de Le Corbusier, criador dos CIAM e autor de algumas das mais belas arquitecturas do movimento moderno, assim como dos mais polémicos textos doutrinários sobre matérias do mundo da arte e da arquitectura. Como garantia de divulgação e procura de popularidade para as suas ideias, Le Corbusier recorria a diversos meios, também com evidente penetração na estrutura profissional em Portugal e Viana transportava o sinal de seu representante como delegado dos CIAM, não só por trajar de modo análogo ao arquitecto suisso, mas também por utilizar sistematicamente o Modular no dimensionamento dos projectos. E por mandar colocar na sala de aula duas tiras coloridas com as sequências rosa e azul, marcando a altura e o comprimento do espaço útil ali em uso, para que os estudantes se familiarizassem com as questões da proporção e da escala humana.

Foi esse exemplo que eu próprio quis ensaiar, realizando os desenhos de uma pequena residência sob a matriz das duas séries de Le Corbusier, ainda que com a descontracção de quem não tinha muita fé naquela mezinha. Na realidade foram apenas números, absolutamente abstractos, os que se alinharam ao longo dos esquissos, sempre dominados por outros princípios mais objectivos como os de tentar cumprir um desígnio projectual comandado pelo enunciado do programa de áreas e funções. E, naturalmente, tendo em atenção as condições construtivas disponíveis na região bem como a vontade de responder com uma imagem forte no processo de transformação do lugar. No final não ganhei a convicção de que com aquele método tenha atingido uma segura proporção entre as partes e de que nada poderia ser reduzido ou acrescentado sem quebra da perfeição. Bem pelo contrário, não cheguei sequer a sentir qualquer vibração interior quando a obra se concluiu. E sei, de fonte segura, que o cliente também não. 


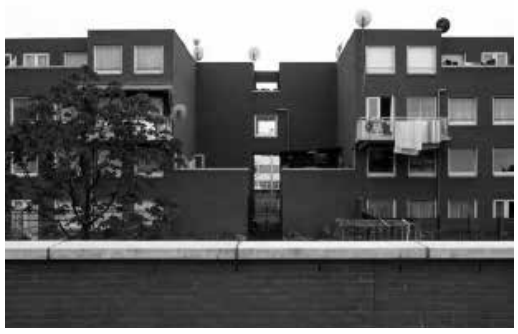

9. Álvaro Siza - Conjunto residencial, Haia, 1983/93
Em Abril voltou finalmente o sol, depois de um longo inverno frio e chuvoso. Havia já cinco anos que o curso de arquitectura tinha rompido com o conceito dominante no ensino universitário que consistia numa estrutura por cadeiras de fornecimento compendiado de saberes, somando competências teóricas na maioria autónomas ainda que complementares, mas por vezes inúteis. É evidente que foi a situação social e política no país que estimulou a crisa específica vivida nas Belas Artes, onde os estudantes eram já politicamente muito activos. Surgiu ali uma situação particular devido a uma forte relação de camaradagem entre professores e alunos, na tradição do ensino-atelier ao modo das Beaux-Arts. Com a queda da ditadura abriu-se um novo espaço de discussão e intervenção, beneficiando da excepcional experiência pedagógica que a prolongada crise da Escola do Porto tinha potenciado. Entre entusiasmos e dramas, venceram-se as disputas internas a caminho de uma nova prática de ensino.

Conheci Álvaro Siza muitos anos antes, ainda estudante de Liceu, é certo que apenas pelo nome e trabalho artístico, quando ele se fez representar numa exposição de desenhos na Galeria Domingues Alvarez ao lado de alguns dos nomes referenciados da vanguarda da arte portuguesa. Como estudante de arquitectura segui regularmente o seu trabalho visitando obras que iam surgindo, descobrindo rolos de esquissos por ele assinados no escritório de Fernando Távora, visitando com curiosidade o seu espaço de trabalho junto à Sé, na vizinhança do de Jorge Gigante, sede do meu emprego regular. Observei a estabilidade das suas teorias sobre a prática da arquitectura e a segurança do seu método assente sobre a constância do desenho, presente em todos os momentos, só ou em convívio, sobre as bases rigorosas preparadas no estirador ou em linhas soltas sucessivas distribuídas pelas folhas brancas dos cadernos A4. Apontamentos de ideias em curso, leituras de projectos de outros mestres, registo descontraído de imagens da envolvente em cada circunstância. Não foi, por isso, surpresa, acompanhar a sua coerência crítica quando trabalhamos juntos a ensinar arquitectura nos terceiro e quarto ano do curso na Escola de Belas Artes do Porto, eu em Projecto e ele em Construção.

A teoria de Siza era simples. Se os estudantes colocassem a compreensão dos processos construtivos e o domínio das técnicas de suporte como matéria de aquisição própria, poderiam compreender o alcance das decisões compositivas quanto à formação da imagem, texturas, ambiências, relação com a envolvente, etc. Expressão firme de uma cultura interventiva. Como caminho para chegar às ideias necessárias, nada como estudar os trabalhos dos mestres, compreender a totalidade dos projectos analisados, desde os fundamentos do problema à particularidade das soluções nas várias vertentes consideradas, sejam as vitruvianas matérias de beleza abstracta, segurança ou adequação às necessidades materiais, seja a contribuição para o enriquecimento das culturas locais, do equilíbrio das paisagens, da significação dos valores propostos. Se de Távora extraíra 
a importância do conhecimento da história como instrumento para pensar a nova arquitectura, Siza ensinou-me a considerar o presente como matéria útil para a história do futuro. E a desafiar os estudantes a procurar um conhecimento mais abrangente e reflectido.

A Revolução de Abril foi também uma revolução na arquitectura. A escola integral, professores e alunos, saíram para a rua, aproveitando os desafios e a dinâmica despoletada pelos partidos políticos em liberdade. Se o povo operário actuou intensamente no emprego, ou por falta dele, as mulheres conduziram a luta na reivindicação de casas dignas de braço dado com os arquitectos, formados ou formandos. No Porto a própria Escola actuou em duas direcções, nem sempre correctamente conjugadas. Por um lado a experiência da acção política dos estudantes da vanguarda mais activa depois de anos de acção clandestina e por outro o saber desenhar com pragmatismo construtivo mas firmeza nas ideias. Em S. Vitor trabalhei com Siza, compondo uma equipa de oito elementos. Para uma Associação de Moradores com seicentos associados, conseguimos produzir dezanove casas. Foi uma lição dura, com pouco proveito directo. Mas sentimos que o nosso contributo também foi importante como método de pensar a arquitectura, abrindo perspectivas muito para além das práticas locais.

Uma proposta consistente foi a ideia de coordenar as intervenções das diferentes equipas, montando um anel de residências populares sobre o centro do Porto, em geito de alternativa ao planeamento tecnocrático vigente. Foi a adopção de uma teoria talvez utópica no quadro dos valores dominantes, mas que se compreende em momentos de profunda e convicta transformação social. Hipótese ainda assim não descartável se quisermos considerar o problema da desertificação dos centros urbanos, com a consciência de que o envelhecimento do parque residencial está profundamente ligado à estrutura da propriedade imobiliária. Pensando, também, que as condições de acesso à habitação em lugares centrais são praticamente inacessíveis aos mais novos, por mais empréstimos bancários que se montem, com renda sob a forma de amortizações e juros. A consciência de outras dimensões para a compreensão dos fenómenos urbanos foi outro património didáctico que se tornou mais claro com o regresso às aulas.

Na prática profissional de Siza, seguida com atenção pelos amigos e companheiros, há a acrescentar outros aspectos metodológicos particularmente importantes. Um deles é o da revisita aos projectos próprios, mesmo se o ponto de partida foi uma sugestão distante encontrada pelos caminhos da história. A proposta desenhada em 1978, vencedora em concurso para uma piscina pública num bairro popular de Berlim, na Alemanha, constituiu um passo seguro na afirmação internacional da figura do arquitecto português. Num contexto urbano difícil, Siza explorou o tema da piscina circular com cúpula ensaiado pelos arquitectos do movimento construtivista russo, numa variação sensível ao problema da relação com a cultura do lugar. Tratou-se de uma linha de pesquiza sobre a experiência mais pura do 


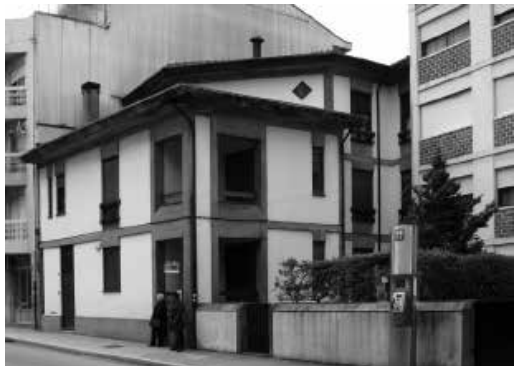

10. Jorge Gigante e Figueiredo Melo - Moradia no Porto, 1958 movimento internacionalista, para conferir a cada obra em concreto as particularidades que a tornem objecto único e próprio do sítio onde se insere. Outra matéria relevante é a procura atenta dos sinais físicos identificadores da cultura do lugar, que se vai instalando com o tempo em função dos hábitos sociais e das práticas construtivas que lhes correspondem. São por vezes aportações subtis que o tempo acaba por consolidar, incorporando na imagem das cidades o específico de uma côr, um material, uma textura, uma escala ou proporção dominante. O projecto para um bairro residencial em Haia é o exemplo flagrante de como se pode ser romano em Roma ou holandês na Holanda, mesmo que se trate de uma comunidade turca com forte autonomia de hábitos e rígidos princípios de vida familiar. E de como à transparência das grandes janelas sobre a rua que fazem o imaginário das cidades de luz frouxa se podem acrescentar os cortinados rendilhados tornando-as mais opacas. Com atenção, podemos perceber que eram estes os ingredientes utilizados pelos arquitectos do Porto quando adaptavam as novidades formais à sua cidade.

Jorge Gigante foi para muitos de nós um exemplo de camaradagem e cidadania, na figura de um arquitecto respeitado pelos seus pares. Cultivava o princípio da solidariedade, entendendo a prática da arquitectura como criação colectiva, privilegiando sempre a acção de grupo com responsabilidades distribuídas mas bem definidas, isentando-se muitas vezes ele próprio de assumir a autoria dos projectos produzidos na sua equipa, quando as circunstâncias do dia a dia o conduziam para outras tarefas. No entanto foi da parceria com Francisco Melo que nasceram algumas das mais brilhantes obras realizadas pelo atelier que ambos criaram. A Central Telefónica do Bonfim é um desses trabalhos que expressa a força da intervenção urbana com recurso a uma solução de grande simplicidade e extrema eficiência. Utiliza um esquema de construção linear e materiais correntes para uma composição de fachada quase cega, ligando dois edifícios preexistentes de dura linguagem contraditória. Insere-se na própria curva da rua enquanto reflecte, graças à placagem de cimento com desenho em rede, o enorme muro de pedra que, em frente, sustem a igreja do Bonfim.

Em coincidência com o período de passagem de aluno de arquitectura a arquitecto tirocinante, convivi durante quatro anos com as pessoas da firma Gigante e Melo. Gigante gostava da vivência em obra, procurando chamar para si tudo o que dizia respeito às relações com o estaleiro nas fases de execução dos projectos. Interessava-lhe o domínio concreto do fazer, não só pela curiosidade sobre o efeito das inovações, mas também pelo convívio alargado com outros especialistas, gestores e operários, colhendo das múltiplas experiências vividas nessas descontraídas reuniões técnicas, lições para os passos seguintes da sua actividade como profissional. Identifico algumas características presentes em todos os projectos desde os primeiros trabalhos da equipa. Em primeiro lugar a procura da continuidade urbana, entendendo 
a obra nova inserida num contexto com carácter perceptível. No exercício do desenho procura sempre as linhas de continuidade e transição de modo a garantir o equilíbrio de todo o sistema abrangido pelo campo visual que afecta a obra. Tenta expressar a matriz construtiva com respeito pela perceptibilidade das lógicas estruturais, bem como do remate dos diversos planos de composição, incluindo diferenciações volumétricas, com recurso à mudança dos materiais de acabamento. Sempre a clareza das soluções para uma correcta compreensão da forma edificada.

Por vezes, encontrar a solução para uma pequena encomenda de natureza corrente pode transformar-se num drama para o arquitecto, bloqueando não só a sua capacidade criativa, mas também o cuidado de se relacionar com verdade junto do seu cliente. Desenhar uma simples moradia de praia transformou-se num complexo de incapacidade perante a evidência do desajuste da encomenda face à desregulação urbana do lugar para que era requerida, num meio de confusas iniciativas imobiliárias. Gigante nunca quiz confessar ao companheiro Melo esse sentimento de desorientação. Durante mais de um ano ignorou o encargo, evitou o cliente, escondeu dos colaboradores a existência de um problema. Até que um dia, quando a pressão atingiu o cúmulo, sentou-se sozinho ao estirador e em menos de uma hora riscou em desenho directo e a rigor a solução total que veio a ser construída. Aprendi nesse dia o poder do drama para despoletar a invenção necessária. Fazer saltar a ideia no momento de pânico que é, afinal, produto da elaboração mental ao nível do inconsciente profundo apelando ao saber e cultura acumulada ao longo da vida. Fenómeno também conhecido por instinto no processo da imaginação criadora.

Durante algum tempo trabalhei com Rolando Torgo no atelier de Jorge Gigante. Personalidade absolutamente distinta de outros profissionais que antes tinha conhecido, ele era o exemplo perfeito do arquitecto discreto. Rolando possuía um temperamento instável, com tendência para trabalhar em concentrado isolamento. Tinha como defeito a constante insatisfação por não poder chegar ao conhecimento seguro e à verdade absoluta, num caminho sem fim. Em arquitectura são sempre inúmeras as alternativas possíveis. A resolução de cada passo era apenas a abertura para a indefinição do passo seguinte. Ouvia ansiosamente a opinião dos colegas mas não se aquietava, perseguindo sem descanso solução sobre solução. E, no entanto, Rolando Torgo tem uma excelente obra realizada, com vários prédios e residências unifamiliares nas encostas à vista de Amarante, debruçados sobre a magnífica paisagem do Rio Tâmega. Em todas elas a luxuriante vegetação domina as subtis paredes caiadas, cuidadosamente articuladas com a acidentada topografia. Exemplos de arquitectura discreta, diriam os teóricos do debate sobre o movimento moderno que é orgânica, porque camuflada no extenso verde duriense.

Com Alcino Soutinho vivi a primeira experiência de intervenção no património construído. $O$ castelo de Vila Nova de Cerveira era 
uma dessas encantadoras velharias da linha das fortalezas de fronteira que serviu no século dezassete durante as guerras da independência. Máquinas militares que perderam todo o sentido operacional.

Em Cerveira o ninho amuralhado abrigava uma capela e algumas casas no seu interior, destinadas à sobrevivência em tempo de guerra. Quando o conheci era um equipamento natural para o povo da Vila, ruína romântica onde se passeava ao domingo, fiscalizando namorados sentados nas ameias viradas ao Rio Minho. Era, mas já não é. Agora tem porteiro com boné de pala, perguntando a quem chega se pretende a pousada ou o restaurante. Não cabe à arquitectura decidir a quem serve o património histórico e a equipa de Soutinho realizou um belo projecto fazendo sair a branca linguagem moderna por cima dos granitos cinzentos carregados de musgo. Neste caso a minha passagem pela equipa foi fugazo, mas suficiente para deixar este amargo sentimento, esta desconfiança sobre que valor e que usos a conferir a estes monumentos sobrantes do passado, não se me tornando muito claro qual deverá ser o registo da mudança ou a intervenção necessária.

Formei-me sob a orientação de vários mestres que entendiam a arquitectura como uma arte dedicada ao desenho do espaço da vivência humana, atenta às singularidades de cada cultura e de cada lugar. Absolutamente avessos a especialidades ou, dizendo de outro modo, o arquitecto é um especialista para os actos de arquitectar a formalização dos espaços da vida social. Da cidade à colher, dizia Fernando Távora. Do detalhe construtivo ao território mais vasto da paisagem transformada. Por isso se entende que Jorge Gigante tenha sido construtor, arquitecto e urbanista com a mesma intensidade. Trabalhou como consultor urbanista em várias Câmaras Municipais. O engenheiro Miguel Resende, director de serviços na Câmara Municipal do Porto, banqueiro e murtuseiro, era um apaixonado pelas práticas desportivas na Ria de Aveiro e puxou Gigante para trabalhar em Concelhos onde tinha sido autor do Ante-Plano Urbanístico.

De entre eles identifico Albergaria-a-Velha e Ovar. Aí se fez sentir a sua sensibilidade para os problemas de natureza paisagista e da cultura arquitectónica no processo de qualificação dos embientes urbanos e rurais. Conduziu com pragmatismo uma acção pedagógica junto de autarcas, promotores do imobiliário, desenhadores e outras forças vivas ou entidades locais.

Jorge Gigante, urbanista da Câmara de Ovar, teve a simpatia de seleccionar um terreno para futura implantação do Museu de Ovar no plano de expansão da cidade para norte, onde se viria a construir o principal núcleo escolar rodeado por alguns complexos habitacionais, pressionando assim o Presidente do Município a reservar com esse fim uma parcela da propriedade pública. O Museu tinha sido constituído como associação cívica de iniciativa particular e vinha reunindo um importante espólio, tanto em materiais da etnografia regional como em obras artísticas de autores modernos de real valor. Passava então por uma fase dinâmica, graças ao empenhamento da sua direcção e à 
real protecção das autoridades locais. Encontrava-se, como ainda se encontra, mal alojado numa casa antiga do centro histórico. Desenvolvi estudos para um novo edifício que se pretendia aberto e moderno, enquadrado pelas escolas. Tiveram início em 1971 e foram prosseguindo nos três anos seguintes até à conclusão do projecto de execução. Constituiu a passagem à prática dos resultados desta odisseia formativa que acabo de descrever. Nele se condensava a lição dos mestres e uma ideia própria de arquitectura, com as ingenuidades próprias de um trabalho saído da fase de tirocínio.

Termino esta memória que não é descritiva do caminho de um estudante de arquitectura, mas que pode ser justificativa de alguns critérios e práticas do ensino da arquitectura que, sinto, integra ainda componentes significativos do património pedagógico da Escola de Coimbra, na parte do que ela pode herdar do patrocínio inicial de Fernando Távora. Outras sensibilidades concorreram para a coerência deste curso e gostaria de lembrar a dedicada contribuição de Raúl Hestnes Ferreira ao longo de uma boa parte destes vinte anos, bem como as de Manuel Taínha e Victor Figueiredo por períodos mais curtos, quando o programa era transformar uma frágil equipa inicial num corpo docente próprio, sólido e permanente. A competência, o prestígio profissional e científico bem como a dedicação da actual equipa docente desta Escola, é garantia de que a Universidade de Coimbra caminhará na vanguarda do ensino da arquitectura em Portugal, honrando o seu prestígio histórico. 